\title{
Irlen syndrome: systematic review and level of evidence analysis
}

\author{
Síndrome de Irlen: revisão sistemática e análise do nível de evidência \\ Jordan Da Silva Miyasaka1, Raphael V. Gonzaga Vieira', Elaine Shizue Novalo-Goto', Erik Montagna', \\ Rubens Wajnsztejn'
}

\begin{abstract}
Background: Scotopic sensitivity syndrome, later called Meares-Irlen syndrome or simply Irlen syndrome (IS) has been described as symptoms of poor reading ability due to poor color matching and distorted graphic images. Individuals with this syndrome are considered slow, ineffective readers with low comprehension and visual fatigue. It is still uncertain whether the disease pathophysiology is an independent entity or part of the dyslexia spectrum. Nevertheless, treatments with lenses and colored filters have been proposed to alleviate the effect of the luminous contrast and improve patients' reading performance. However, no evidence of treatment effectiveness has been achieved. Objective: The aim of the present study was to obtain evidence about IS etiology, diagnosis and intervention efficacy. Methods: A systematic review was performed covering the available studies on IS, assessing the available data according to their level of evidence, focusing on diagnostic tools, proposed interventions and related outcomes. Results: The data showed high heterogeneity among studies, and lack of evidence on the existence of IS and treatment effectiveness. Conclusion: The syndrome as described, as well as its treatments, require further strong evidence.
\end{abstract}

Keywords: Reading disorders; systematic review; evidence-based medicine; meares-irlen syndrome; colored lenses.

\section{RESUMO}

Background: A síndrome da sensibilidade escotópica, posteriormente denominada síndrome de Meares-Irlen ou simplesmente síndrome de Irlen (SI), foi descrita como indivíduos com sintomas de baixa capacidade de leitura devido à combinação de cores e distorções nas imagens. Indivíduos com essa síndrome podem apresentar leitura lenta e ineficaz, com baixo nível de compreensão e fadiga visual. A fisiopatologia da doença ainda é incerta como uma entidade independente ou como parte do espectro da dislexia. No entanto, tratamentos com lentes e filtros coloridos foram propostos com o objetivo de aliviar o efeito do contraste luminoso e melhorar o desempenho de leitura dos pacientes. Outrossim, nenhuma evidência de eficácia do tratamento foi alcançada. Objetivos: Obter evidências sobre a etiologia, eficácia diagnóstica e intervenção da SI. Métodos: Foi realizada uma revisão sistemática, cobrindo os estudos disponíveis sobre a SI, avaliando os dados disponíveis de acordo com seu nível de evidência, com foco em ferramentas de diagnóstico, intervenções propostas e desfechos relacionados. Resultados: Os dados mostram alta heterogeneidade, falta de evidência sobre a existência da SI e eficácia do tratamento. Conclusões: A síndrome descrita e seus tratamentos exigem evidências mais robustas.

Palavras-chave: Transtorno da leitura; revisão sistemática; medicina baseada em evidência; síndrome de meares-irlen; lentes coloridas.

The scotopic sensitivity syndrome was identified in 1980 by the clinical picture of complaints of perceptual dysfunction according to the light source, luminance, intensity, wavelength and color contrast ${ }^{1}$. Subsequently, individuals with similar symptoms were also identified with reading difficulties due to poor adaptation to color contrasts (light and dark) and distorted graphic images. All these signs were labeled the Irlen syndrome (IS) ${ }^{2}$.

This visual alteration was subdivided into six groups: people with photophobia (sensitivity to brightness); distortion of the fundus (difficulty of adaptation between contrasts such as light and dark); graphical distortions during reading (sensation of movement of the letters); decreased visual field (clear image in the center with peripheral cloudiness); difficulty in ocular fixation during reading; and change in depth perception ${ }^{2}$. Studies have reported that the scotopic sensitivity syndrome, or IS, (and even Meares-Irlen syndrome), may result in a slow, ineffective and poorly comprehended ability to read, as well as causing fatigue and tension to the reader ${ }^{3,4}$.

\footnotetext{
${ }^{1}$ Faculdade de Medicina do ABC, Santo André SP, Brasil.
}

Erik Montagna (iD https://orcid.org/0000-0001-6834-0261;

Correspondence: Erik Montagna; Faculdade de Medicina do ABC - Pós-Graduação; Av Lauro Gomes, 2000; 09060-870 Santo Andre SP, Brasil; E-mail: erik. montagna@fmabc.br

Conflict of interest: There is no conflict of interest to declare.

Received 05 April 2018; Received in final form 26 September 2018; Accepted 07 November 2018. 
The pathophysiology of IS is claimed to be associated with changes in the visual cortex and deficits of the magnocellular system, which is important during reading, and for the acquisition of information from the visual system on movement ${ }^{3,5,6}$. Some studies have claimed that IS has a genetic component and is related to specific biomarkers, affecting both sexes, and manifesting itself in different degrees of impairment ${ }^{7,8}$.

Current treatment recommends the use of filters and colored lenses in order to reshape the light spectrum, reducing the contrast between light and dark to facilitate visual and retinal photoreceptor adaptation. According to the data at the time of publication, patients would be able to improve their comprehension of reading, attention, sensation of depth, fatigue symptoms, among others, by wearing these colored lenses ${ }^{2,6}$. Despite these reports ${ }^{9}$, little data about the level of evidence for IS, or the treatments proposed by its advocates, are available. Finally, evidence for the IS itself and even the legitimacy of the therapeutic approach became questionable after the emergence of data regarding the effect of the lenses being indistinguishable from placebo ${ }^{10}$.

Thus, the objective of the present study was to carry out a systematic review, with wide coverage on IS existence, the use of colored lenses as a therapeutic approach and its effectiveness, evaluating the available data according to their level of evidence.

\section{METHODS}

A systematic review was performed according to the PRISMA $^{11}$ statement. Databases searched covered PubMed, Embase, PsycNET, ERIC, Cochrane, Clinical Trials, LILACS and ScieLO, without time span constraints. In order to achieve wider coverage, we first used ("irlen" OR "Irlen" OR "Irlen-Meares") in PubMed and then "Irlen" as the unique search term for "All Fields". The same strategy was performed for the other databases.

\section{Selection of studies}

Inclusion criteria: studies having an IS diagnosis; studies where colored lenses (or filters) were used as an intervention. Exclusion criteria: reviews; when IS was not the study subject; idiom that none of the authors could read; letters to the editor, comments or merely specialists' point of view; nonpeer reviewed articles, grey literature and unindexed or predatory journals.

\section{Data extraction}

Two investigators independently extracted data (EM, JSM). The following information was retrieved from the studies: first author's name, publication year, population characteristics (type, size, sex, age), the existence of a comparison group, study type, presence of sample size calculations, tools used for IS diagnosis, intervention (when possible), color filter wavelength measurement, study outcomes, reading rate modification observed, risk of bias, main conclusions and level of evidence.

\section{Level of evidence}

Retrieved articles were classified according to the Oxford Center for Evidence-Based Medicine's (OCEBM) ${ }^{12}$ level of evidence. Three independent reviewers (JSM, RVGV, ESNG) determined the level of evidence classification individually. Although discrepancies were rare, the highest level of evidence was used on ties. Data extraction and summaries of data were performed by two independent groups of two reviewers (EM, JSM and RVGV, ESNG). Ties were dismissed by RW.

The OCEBM classification comprises five levels of evidence for each type of study target (treatment/prevention, prognosis, differential diagnosis and diagnosis/symptom prevalence study). Level I therapeutic studies comprise systematic reviews with meta-analysis of randomized clinical trials (Ia) and well-designed individual randomized clinical trials (Ib). Level II comprises systematic reviews of cohort studies (IIa), individual cohort studies, randomized clinical trials with less than $80 \%$ follow-up (IIb) and ecological studies (IIc). Level 3 comprises reviews of casecontrol (IIIa) and individual case-control (IIIb) studies. Level 4 covers case-control and low-quality cohort studies (absence of blinding or presence of biases and trend of results). Finally, level 5 consists of expert opinions, without critical evaluation, or based on physiology, database search or "first principles".

In this classification, there is no inclusion of descriptive or opinion studies. Thus, we overestimated these types of works for level 5 in order to include them as potential sources of information. This adjustment was based on the World Health Organization criteria for the level of evidence ${ }^{13}$, however the OCEBM was the main instrument.

\section{RESULTS}

\section{Systematic review and summary of evidence}

There are no MeSH terms in PubMed for Irlen Syndrome, Meares-Irlen Syndrome or Scotopic Sensitivity Syndrome; the Emtree suggests Irlen as a referred term, not an entry term, as does PsycNET and the Cochrane Database.

Figure 1 outlines our study selection process in a PRISMA flowchart ${ }^{11}$.

The complete summary of findings is available as supplemental material due to space constraints. It was not possible to perform a meta-analysis due to great variations in study types, critical biases, extremely heterogeneous groups and generally low standards, as will be demonstrated below. Nevertheless, summarized data is shown in the Table. The 


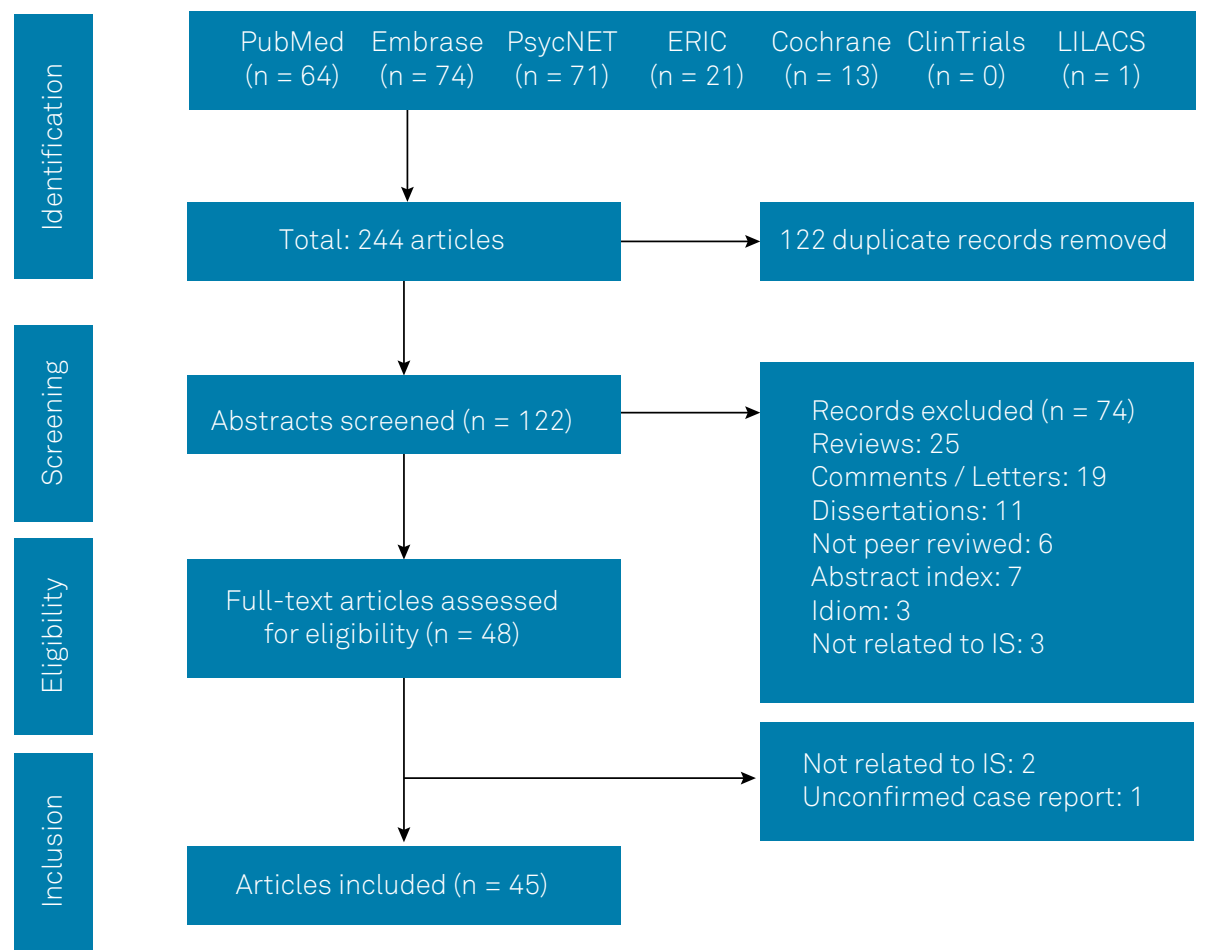

Figure 1. Flow diagram of study selection according to the PRISMA statement.

main findings are presented in the Table, ordered by publication date.

\section{Summary}

The interval time between all publications varied from 1989 to 2018. The sum of narrative reviews, letters, comments or responses comprised 44 articles, about one-third of all references regarding IS, which corroborates the controversy on the subject. The same proportion of original articles was retrieved for the summary $(n=45)$.

From the studies summarized, 21 were published in Ophthalmology or Optometry journals; and 27 studies were published in the same four journals. One author ${ }^{17}$ appears in 11 of the 45 studies; another one ${ }^{23}$ appears in 10 and owns the property of several patents related to the diagnosis and intervention in IS; a third author appears in six studies.

The sum of all participants studied was 3,963 (mean/ SD of $90.07 \pm 132.8$ ), with an irregular distribution between male and female participants, as well their ages or the presence of individuals with comorbidities, irregular distribution of methods, such as the absence of an ophthalmic or optometric evaluation in many cases, as well as other characteristics, revealing the heterogeneity. However, removing study participants from the strictly epidemiological articles reduced the main sample to 2,281 subjects (with mean/SD of $57.03 \pm 47.87$ ); five of these studies $^{28,29,33,49,52}$ comprised a total of 1,682 participants (with mean/SD of $420.5 \pm 250.7$ ). Even with these adjustments, the whole sample remained heterogeneous.
Along with that, as three different studies ${ }^{25,26,30}$ shared the same group of patients and part of the data, they could not be summed for effect size. It is worth noting that they shared other characteristics described in several parts in the published articles. Other studies ${ }^{28-31}$ partially used the samples from the same group in the same location for slightly different analyses.

Study types were varied and, although some of them claimed a certain design, it is arguable whether they followed the mentioned design. Only two studies ${ }^{44,45}$ provided sample size estimations in their design in order to find populational significance; 15 studies did not have proper control groups, ranging from undiagnosed or self-referred asymptomatic individuals, to the declared lack of control group where needed.

A large study on IS prevalence was performed with 450 participants, aged 18 to $30^{49}$, all female, and the authors did not perform any of the procedures for IS detection. Instead, a survey was spread among a nonrandomized population. Another large prevalence study ${ }^{51}$ comprised 486 males and 265 females from ages 7 to 17; yet another ${ }^{28}$, analyzed data from 323 participants aged 4 to 73 years and, finally, a study ${ }^{31}$ covered 158 participants aged 7 to 13 . Even with considerable sample sizes, their heterogeneity is a matter of concern.

Ten tests for IS diagnosis were identified, where seven were proprietary and patented; in some cases, it was difficult to discriminate when the tests were interchangeable, were improved versions of the same test or new ones ${ }^{53}$. Along with these, 21 other tests were performed either for tool comparison or confirmation of the presence of IS. Only two studies ${ }^{10,44}$ 
Table. Summary of evidence (resumed version).

\begin{tabular}{|c|c|c|c|c|c|c|c|}
\hline \multirow{2}{*}{ Reference } & \multicolumn{2}{|c|}{ Population } & \multirow{2}{*}{$\begin{array}{l}\text { Study } \\
\text { type }\end{array}$} & \multirow{2}{*}{$\begin{array}{l}\text { Diagnostic } \\
\text { tool }\end{array}$} & \multirow{2}{*}{ Intervention } & \multirow{2}{*}{ Main findings } & \multirow{2}{*}{$\begin{array}{l}\text { Level of } \\
\text { evidence }\end{array}$} \\
\hline & Population & Comparison group & & & & & \\
\hline $\begin{array}{l}\text { O'Connor et al. } \\
1990^{14}\end{array}$ & 92 Children & Non-scotopic & $\mathrm{CC}$ & $\begin{array}{l}\text { IDPS } \\
\text { NARA } \\
\text { FRI }\end{array}$ & $\begin{array}{l}\text { PCOF } \\
\text { DCOF }\end{array}$ & $\begin{array}{l}\text { More visual comfort. } \\
\text { Gained reading rate. } \\
\text { Filter improved reading. }\end{array}$ & 3 \\
\hline $\begin{array}{l}\text { Scheiman et al. } \\
1990^{15}\end{array}$ & $\begin{array}{l}\text { Varied } \\
\text { (age } 10 \text { to 49) } \\
n=39\end{array}$ & No control & $\mathrm{CH}$ & IDPS & & $\begin{array}{l}\text { More visual comfort. } \\
\text { Gained reading rate. } \\
\text { Filter improved reading. }\end{array}$ & 4 \\
\hline $\begin{array}{l}\text { Blaskey et al. } \\
1990^{16}\end{array}$ & $\begin{array}{l}\text { Varied } \\
\text { (age } 9 \text { to } 51 \text { ) } \\
12 \text { male; } 18 \\
\text { female }\end{array}$ & Non-scotopic & $\mathrm{CCH}$ & IDPS & IF & $\begin{array}{l}\text { Self-declared more comfort. } \\
\text { No gain in reading. } \\
\text { Irlen filter group showed no } \\
\text { significant gains. }\end{array}$ & 4 \\
\hline $\begin{array}{l}\text { Robinson, } \\
\text { Conway } 1990^{17}\end{array}$ & $\begin{array}{l}\text { Varied } \\
\text { (age } 9 \text { to 15) } \\
33 \text { males, } 11 \\
\text { female }\end{array}$ & No control & $\mathrm{CH}$ & $\begin{array}{l}\text { IDPS } \\
\text { NARA } \\
\text { SPAS }\end{array}$ & IF & $\begin{array}{l}\text { Improvements on Irlen tests. } \\
\text { No improvements on NARA } \\
\text { and SPAS. } \\
\text { Filter improved reading } \\
\text { accuracy and comprehension, } \\
\text { but not rate. }\end{array}$ & 4 \\
\hline $\begin{array}{l}\text { Martin et al. } \\
1993^{18}\end{array}$ & $\begin{array}{c}\text { 7th graders } \\
n=60\end{array}$ & Normal readers & $\mathrm{CCH}$ & $\begin{array}{l}\text { LILP } \\
\text { NARA } \\
\text { RPM } \\
\text { NWT }\end{array}$ & IL/COF & $\begin{array}{l}\text { No difference among groups. } \\
\text { No gain in reading. } \\
\text { No improvement with IL/COF. }\end{array}$ & 4 \\
\hline $\begin{array}{l}\text { Carrol et al. } \\
1994^{19}\end{array}$ & $\begin{array}{c}\text { Varied } \\
\text { (age } 10 \text { to 20) } \\
n=64\end{array}$ & 23 normal readers & $\mathrm{CC}$ & IDPS & $\begin{array}{c}\text { Dark } \\
\text { adaptation }\end{array}$ & $\begin{array}{l}\text { No difference among groups. } \\
\text { Inconclusive. }\end{array}$ & 4 \\
\hline $\begin{array}{l}\text { Evans et al. } \\
1994^{20}\end{array}$ & $\begin{array}{l}\text { Varied (mean } \\
\text { age 22; age } 7 \\
\quad \text { to } 12 \text { ) } \\
\quad n=82\end{array}$ & 11 normal readers & $\mathrm{CC}$ & $\begin{array}{l}\text { PGT } \\
\text { SRVST } \\
\text { NARA }\end{array}$ & $\mathrm{COF}$ & $\begin{array}{l}\text { No difference with lenses. } \\
\text { No differences in PGT among } \\
\text { groups. } \\
\text { Borderline significance } \\
\text { supporting lenses. }\end{array}$ & 4 \\
\hline $\begin{array}{l}\text { Lopez et al. } \\
1994^{21}\end{array}$ & $\begin{array}{l}\begin{array}{l}\text { Varied } \\
\text { (children) }\end{array} \\
39\end{array}$ & $\begin{array}{c}15 \text { with "academic } \\
\text { problems" }\end{array}$ & $\mathrm{CC}$ & ISSST & PCOF & $\begin{array}{l}\text { No difference in PCOF users. } \\
\text { No difference in academic } \\
\text { performance. } \\
\text { More research needed. }\end{array}$ & 4 \\
\hline $\begin{array}{l}\text { Sawyer et al. } \\
1994^{22}\end{array}$ & $\begin{array}{l}\text { Varied (age } 7 \\
\quad \text { to } 15 \text { ) } \\
n=271\end{array}$ & $\begin{array}{l}86 \text { children } \\
\text { without referred } \\
\text { reading problems }\end{array}$ & $\mathrm{CC}$ & SRTa & PCOF & $\begin{array}{l}\text { Differences inside the } \\
\text { instrument variation. } \\
\text { No improvement in reading. } \\
\text { Very low effect; other } \\
\text { refractive problems as the } \\
\text { cause; more investigation } \\
\text { needed. }\end{array}$ & 4 \\
\hline $\begin{array}{l}\text { Wilkins et al. } \\
1994^{23}\end{array}$ & $\begin{array}{l}\text { Varied } \\
\text { (age } 9 \text { to } 15 \text { ) } \\
n=37\end{array}$ & $\begin{array}{l}\text { Children with } \\
\text { reported failing in } \\
\text { reading, with and } \\
\text { without lenses. }\end{array}$ & PCT & $\begin{array}{l}\text { ISSST } \\
\text { NARA }\end{array}$ & $\begin{array}{c}\text { Intuitive } \\
\text { Colorimeter }\end{array}$ & $\begin{array}{c}\text { No differences on NARA and } \\
\text { other symptoms evaluated. } \\
\text { No gain in reading. } \\
\text { Lenses ameliorate symptoms } \\
\text { of IS. }\end{array}$ & 2 \\
\hline $\begin{array}{l}\text { Evans et al. } \\
1995^{24}\end{array}$ & $\begin{array}{l}\text { Children aged } \\
\qquad \begin{array}{c}12 \\
n=42\end{array}\end{array}$ & $\begin{array}{c}26 \text { nonresponsive } \\
\text { to COF }\end{array}$ & $\mathrm{CC}$ & NARA & $\begin{array}{l}\text { Intuitive } \\
\text { Colorimeter }^{\circledR}\end{array}$ & $\begin{array}{l}\text { No differences on NARA or } \\
\text { symptoms. } \\
\text { No gain in reading. } \\
\text { Suggests caution on data } \\
\text { interpretation due to high } \\
\text { similarity among case and } \\
\text { control groups. }\end{array}$ & 4 \\
\hline
\end{tabular}




\begin{tabular}{|c|c|c|c|c|c|c|c|}
\hline $\begin{array}{l}\text { Spafford et al. } \\
1995^{25}\end{array}$ & $\begin{array}{l}\text { Adult and } \\
\text { children } \\
4 \text { children, } 4 \\
\text { adults }\end{array}$ & $\begin{array}{l}8 \text { matched } \\
\text { controls }\end{array}$ & $\mathrm{CC}$ & WRAT-R & COF & $\begin{array}{l}\text { No differences on WRAT-R. } \\
\text { Lens color not critical for } \\
\text { reading. } \\
\text { Inconclusive; use of any } \\
\text { unproven therapy could delay } \\
\text { appropriate treatment. }\end{array}$ & 4 \\
\hline $\begin{array}{l}\text { Evans et al. } \\
1996^{26}\end{array}$ & $\begin{array}{l}\text { Reports on } \\
\text { sample from } \\
\text { previous study } \\
\text { (25) }\end{array}$ & $\begin{array}{l}\text { Participants } \\
\text { report failing in } \\
\text { reading, with/ } \\
\text { without lenses. }\end{array}$ & $\mathrm{CC}$ & $\begin{array}{c}\text { ISSST } \\
\text { PGT } \\
\text { Optometrics }\end{array}$ & COF & $\begin{array}{l}\text { No difference in pattern glare } \\
\text { and IS. } \\
\text { Ocular motor anomalies } \\
\text { correlate to IS. } \\
\text { Method psychophysically } \\
\text { primitive; optometric } \\
\text { anomalies are priority in } \\
\text { treatment. }\end{array}$ & 4 \\
\hline $\begin{array}{l}\text { Ciuffreda et al. } \\
1997^{27}\end{array}$ & $\begin{array}{l}\text { Adults } \\
\text { (age } 18 \text { to } 39 \text { ) } \\
2 \text { males; } 6 \\
\text { females }\end{array}$ & No & $\mathrm{OB} / \mathrm{CR}$ & LILP & COF & $\begin{array}{l}\text { No positive effect on } \\
\text { steady-state } \\
\text { accommodation. } \\
\text { No improvement on accuracy; } \\
\text { participants in fact needed } \\
\text { other vision intervention. }\end{array}$ & 4 \\
\hline $\begin{array}{l}\text { Evans et al } \\
1999^{28}\end{array}$ & $\begin{array}{l}\text { Varied } \\
\text { (age } 4 \text { to } 73 \text { ) } \\
N=323\end{array}$ & No & RP/EP & $\begin{array}{l}10 \\
1 C\end{array}$ & PCOF & $\begin{array}{l}\text { Patient perception of } \\
\text { improvement. } \\
\text { 73\% still wearing tinted } \\
\text { lenses 1,5 yrs after. }\end{array}$ & 4 \\
\hline $\begin{array}{l}\text { Robinson, } \\
\text { Foreman } 1999^{29}\end{array}$ & $\begin{array}{l}\text { Children } \\
\text { (age } 9 \text { to } 13 \text { ) } \\
n=113\end{array}$ & $\begin{array}{l}35 \text { controls with } \\
\text { reading problems }\end{array}$ & РCT & $\begin{array}{l}\text { ISSST/LILP } \\
\text { NARA }\end{array}$ & $\mathrm{IL}$ & $\begin{array}{l}\text { No difference among groups. } \\
\text { No modification related to } \\
\text { other groups. } \\
\text { No improvements at all. }\end{array}$ & 2 \\
\hline $\begin{array}{l}\text { Robinson, } \\
\text { Foreman } 1999^{30}\end{array}$ & $\begin{array}{c}\text { Same as } \\
\text { previous (32) } \\
n=88\end{array}$ & $\begin{array}{l}28 \text { controls from } \\
\text { previous study ( } 32 \text { ) }\end{array}$ & РCT & $\begin{array}{l}\text { ISSST/LILP } \\
\text { NARA }\end{array}$ & IL & $\begin{array}{l}\text { Statistical difference among } \\
\text { selected groups. } \\
\text { Improvements on some tasks. }\end{array}$ & 2 \\
\hline $\begin{array}{l}\text { Robinson et al } \\
2000^{31}\end{array}$ & $\begin{array}{c}\text { Varied } \\
\text { (age } 9 \text { to 13) } \\
n=158\end{array}$ & $\begin{array}{l}125 \text { referred } \\
33 \text { screening }\end{array}$ & PP & $\begin{array}{l}\text { ISSST } \\
\text { IS }\end{array}$ & - & $\begin{array}{c}\text { 84\% of parents with IS } \\
\text { No difference among groups } \\
\text { Prevalence of symptoms on } \\
\text { males }\end{array}$ & 4 \\
\hline $\begin{array}{l}\text { Bouldoukian et } \\
\text { al. } 2002^{32}\end{array}$ & $\begin{array}{c}\text { Varied } \\
\text { (age } 7 \text { to 40) } \\
n=33\end{array}$ & $\begin{array}{l}\text { With/without } \\
\text { overlay }\end{array}$ & $\mathrm{CC}$ & $\begin{array}{c}\text { IO } \\
\text { WRRT }\end{array}$ & 10 & $\begin{array}{c}\text { Increased reading rate due } \\
\text { to } 10 . \\
\text { Increased rate due to practice } \\
\text { on same test. } \\
\text { IO improved rate of reading. } \\
\text { No placebo effect. }\end{array}$ & 2 \\
\hline $\begin{array}{l}\text { Evans, Joseph } \\
2002^{33}\end{array}$ & $\begin{array}{l}\text { University } \\
\text { students } \\
n=113\end{array}$ & $\begin{array}{l}13 \text { participants } \\
\text { without } \\
\text { complaints }\end{array}$ & $\mathrm{CC}$ & $\begin{array}{c}\text { IO } \\
\text { WRRT }\end{array}$ & 10 & $\begin{array}{l}\text { More than } 90 \% \text { was } 3,8 \% \\
\text { faster with } 10 \text {. } \\
21 \text { participants stated that } 10 \\
\text { worsened perception. } \\
\text { One-third of the } \\
\text { sample shows benefit on } \\
\text { reading }(>5 \%) \text { with } \\
\text { colored lenses. } \\
\text { Prevalence in adults equal in } \\
\text { children. }\end{array}$ & 4 \\
\hline $\begin{array}{l}\text { Scott et al. } \\
2002^{34}\end{array}$ & $\begin{array}{l}\text { Children } \\
\text { (age } 10 \text { to } 12 \text { ) } \\
n=94\end{array}$ & $\begin{array}{l}63 \text { without IS } \\
\text { criterion }\end{array}$ & CC & $\begin{array}{l}\text { IO, WRRT, } \\
\text { LRT }\end{array}$ & 10 & $\begin{array}{l}\text { No difference among groups } \\
\text { with and without } 10 \text {. } \\
\text { Supports the beneficial } \\
\text { effects of } 10 \text {. }\end{array}$ & 4 \\
\hline
\end{tabular}

Continue 


\section{Children}

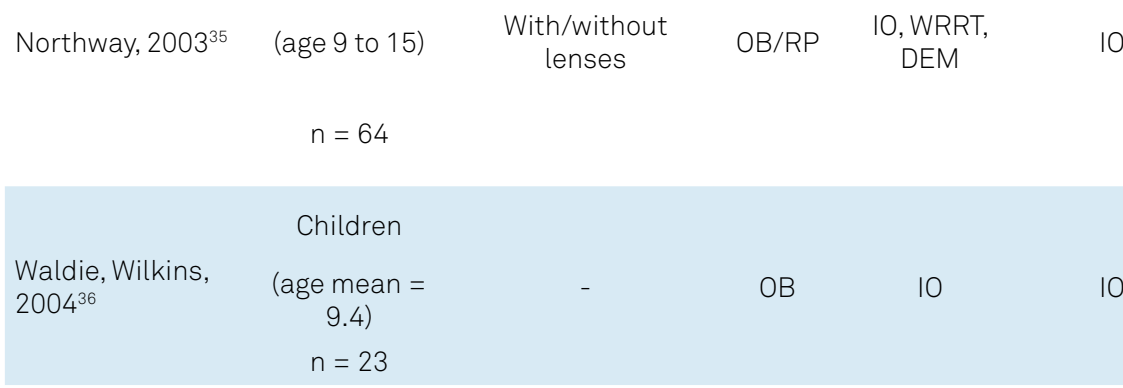

Children

$\begin{array}{lccc} & \text { (age } 7 \text { to } 12) & \text { CC with } \\ \text { Kriss, Evans, } & & \text { 32 dyslexic; with / } & 2 \times 2 \\ 2005^{37} & n=64 \text { dyslexic } & \text { without } 10 & \text { mixed } \\ \text { factorial }\end{array} \quad$ IO, WRR

\section{0}

Adults

Hollis, Allen, $2006^{38}$ (age 18 to 58)

$$
n=58
$$

Children

Riddel et al. $2006^{39}$

(age 9 to 16)

10 (6 male; 4

female)

Children
Kruk et al. $2008^{40} \quad$ (age 9 to 10) 18 non-dyslexic OB/PP IRPS, LILP,
$n=36$

\section{Children}

(age 7 to 11)

\begin{tabular}{|c|c|c|c|}
\hline $\begin{array}{l}\text { Mitchell et al. } \\
2008^{10} \text {. }\end{array}$ & $\begin{array}{c}\mathrm{n}=49(35 \\
\text { male, } 14 \\
\text { female) }\end{array}$ & $\begin{array}{l}\text { With/without } \\
\text { lenses }\end{array}$ & PCT \\
\hline
\end{tabular}

No significant difference among groups; no increase in reading speed.

Improvement only on WRRT, not DEM.

4

Visual symptomatic children found a preferred colored overlay of benefit.

No significant difference among groups

Control group w. higher scores in WRRT;

$34 \%$ of dyslexic group up to $8 \%$ faster on WRRT with 10 .

4

IS affected normal readers.

Although no significant difference in prevalence, more IS in dyslexic children.

No benefit of 10 for normal.

Self reported symptom.

Reading speed test recommended.

No significant differences among groups.

No objective VEP

differences can be measured

in all children who claim benefit from the use of colored lenses.

No difference among normal readers and dyslexic.

IS diagnosis was not an indicator of visual deficit subtype of dyslexia.

No relationship between IS and reading performance.

NARA and SDMT improved in all groups.

IDPS improved in placebo and experimental, and decreased in control.

No difference among placebo and experimental groups.

Clear definition of visuoperceptual reading disabilities impaired the possible conclusion and experimental design.

$24 \%$ revealed IS

University

students

Nichols et al. (mean age

$$
\text { 23.4) }
$$

$\mathrm{OB} / \mathrm{PP}$

IO, WRRT,

LADS
4 
Adults

Taub et al. $2009^{42}$
$N=60$
No referred symptoms of IS
OB/PP Visagraph ${ }^{\circledR}$

No improvement in reading.

No difference among groups.

The IS symptoms were related to binocular/accommodative vision disorder.

Children

school)

Ritchie et al. $2011^{43}$

$n=75$
No gain in reading.
$-$

\begin{abstract}
OB/PP
\end{abstract}
LILT, WRRT, MMSE, GORT
IO No difference among groups for all tests.

More orthoptic problem in IS group.
Secondary

students

Vidal-López $2011^{44}$

(mean age 12)

$n=54(28$

males)

\section{7 paired}

individuals without IS
PGT, IO, ISSST,

CC
VS-SDT stress theory. Suggested
IS children (mean age 9)

Ritchie et al. $2012^{45}$
10 non-IS

$\mathrm{CC} / \mathrm{CH}$

(1yr) MMSE, GORT
10

$\begin{array}{lllll} & \\ \text { IS students } & & & \\ \text { Chang et al. } & \text { (age } 8 \text { to } 34) & \text { 11 dyslexic } & \text { CC } & \text { Not } \\ \text { specified } & \text { IO Korea }\end{array}$

\begin{tabular}{|c|c|c|c|c|c|}
\hline \multirow{3}{*}{ Kim et al. $2015^{47}$} & Varied & & & & \\
\hline & (age 13 to 41 ) & - & OB/PP & $\begin{array}{c}\text { Self-reported } \\
\text { IS }\end{array}$ & 10 \\
\hline & $n=15$ & & & & \\
\hline
\end{tabular}

Non-clinical

samples

Loew et al. $2015^{48}$ (age 21 to 60)

With/without lenses.
Self-reported; WRRT; Tinted lenses PROLEC;IO
No differences with 10 users.

Attributional bias.

Did not support the visual strong motivational effects.

No difference among groups.

No improvements with 10 after $1 \mathrm{yr}$.

No benefits to reading. No effects in short or long term. Improvement needed on IS diagnosis.

Lenses efficacy should be measured.

Objectively testing for the syndrome.

Further studies required.

Brain reacts different with and without lenses.

Temporal regions activate after lenses. 
performed psychophysical tests. Nevertheless, the use of validated tests was rarely reported.

Interventions were, in most cases, the use or not of colored lenses. However, this was a confounding factor, because colored lenses were one of the identification tools proposed to determine IS. Fifteen studies carried some kind of wavelength measurement for the color filter instead of simply declaring a color for the filter. Of these, four used physical measurements ${ }^{23,32,48,54}$ and the other 11 studies used a patented method for a color search instead of instrumental wavelength measurements.

The main conclusions were unequivocal about the positive effects of the lenses or as supportive for IS in 14 of the 45 studies. On the other hand, 14 studies claimed the opposite; five stated that studies were inconclusive and four suggested further studies. Diverse conclusions emerged from the other eight studies.

The level of evidence according to the OCEBM is shown in Figure 2.

A total of five articles were classified as level 2 of evidence and three as level 3. As mentioned above, comments and letters were pushed up in their classification to level 5 of evidence in order to consider specialized opinion.

The main findings of the upper level classified articles are presented below.

\section{Level 1}

Griffiths et al. ${ }^{9}$ presented a comprehensive systematic review of the literature and was not limited to IS, but to the effect of colored lenses in different situations. In this article, 51 studies covering 244 patients were analyzed. Inclusion criteria were randomized clinical trials and exclusions were the absence of a control group and absence of a formal reading measurement. Of the studies analyzed, 15 were related to the use of lenses with colored filters for reading in IS. It was concluded that the use of colored lenses to improve reading in individuals with IS could not be proven based on the existing literature, regardless of the type of color system used for the study. In addition, two trials with the lowest risk of bias failed to demonstrate any improvement in reading through the use of the prescribed lenses ${ }^{29,30}$. None of the studies with low risk of bias or high statistical value corroborated the aid of lenses in reading. The majority of studies were subject to 'high' or 'uncertain' risk of bias in one or more key aspects of study design or outcome. Studies at lower risk of bias provided less support for the benefit of colored lenses/ overlays on reading ability. While many studies reported improvements with colored lenses, the effect size was generally small and/or similar to the improvement found with a placebo condition.

Galushka and Schulte-Körne ${ }^{5}$ performed a systematic review and meta-analysis that aimed at the development of guidelines for the diagnosis and treatment of reading and/or spelling disorders in children and adolescents in Germany. Among several results, they showed robust data from a metaanalysis where Irlen lens efficacy was not confirmed. They claimed that IS is a non-symptom-oriented intervention with or without the lack of evidence. They also state, within their higher grade of recommendation, that Irlen lenses should not be used.

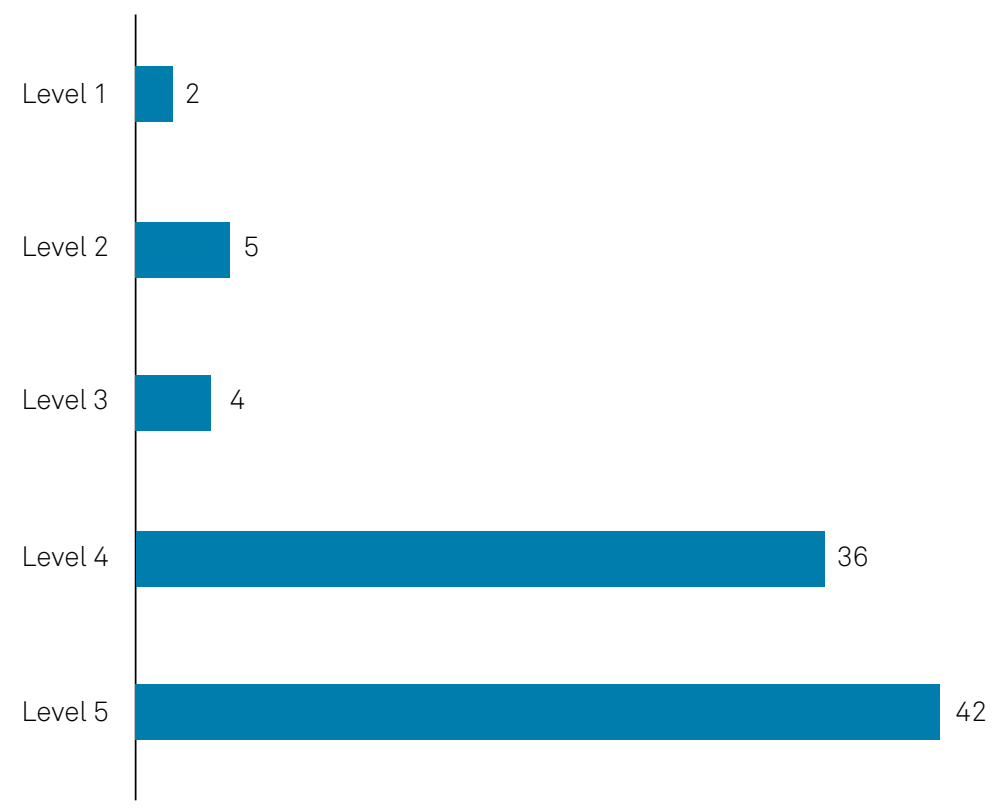

The figure depicts the distribution of studies according to the Oxford Center for Evidence Based Medicine. The 'y' axis represents the levels of evidence without subdivisions; The ' $x$ ' axis is the total number of articles assessed and attributed to each level. The right side of the bars shows the absolute number of articles on each level. Despite the general acceptance of a pyramid-shape, there is an evident absence of higher-level studies on the subject.

Figure 2. Level of evidence of the articles. 


\section{Level 2}

Wilkins et al. ${ }^{23}$ performed a double-blind placebo-controlled trial of colored filtered lenses in children. Like the previous study, a strong selection bias for experimental and control groups was seen when the authors claimed they selected children "who reported benefit" from the study subject. The study also showed a very low size effect and assessment data based solely on the children's opinions and perceptions. Finally, the authors themselves reported no differences in assessment between group and control; however, they reported less frequent symptomatology among the experimental group.

In the studies by Robinson and Foreman ${ }^{29,30}, 113$ individuals aged between 9-13 years, with poor reading and IS, were recruited and randomly allocated to one of three experimental groups: with properly prescribed (optimal or ideal) colored lenses $(n=38)$, with a blue lens $(n=41)$ or with a placebo lens, similar to the ideal lenses but not improving visual symptoms $(n=34)$. In the study, there was also a control group $(\mathrm{n}=35)$ with poor reading skills but no IS. This control group was recruited from a local school, different from the experimental group, thus creating a potential selection bias. Although described as a 20-month long-term placebo-controlled study, the participants only started using the recommended lenses after the first three months. In the beginning no difference between groups in any reading measurement was observed. The group with ideal lenses presented with values slightly lower than the others. After three months, all groups showed improvements on reading tests, with no significant difference among them. It was suggested that this result occurred due to reading practice and not to the lenses themselves. Although there was improvement in textual comprehension in the group with optimal lenses, comparisons between groups in a parallel group study should be analyzed carefully ${ }^{6}$. As well, both studies were carried out with selection bias for the studied groups. They used several selfreported instruments for the main assessments in reading and, finally, reported a nonsignificant increase in the rate of reading ${ }^{29}$ and a failure to find significant improvement for the experimental groups ${ }^{30}$.

Bouldoukian and colleagues ${ }^{32}$ carried out a randomized control trial with 33 participants, comprising children and adults for testing the effects of colored Irlen lenses. Even though it was claimed to be a randomized control trial, the study had major flaws in design. The group selection was biased by inclusion of individuals who knew their condition; very low size effect with misleading percent data; arguable randomization protocol; and assessment data based on selfreported tasks and merely asked preferences.

\section{Level 3}

O'Connor et al. ${ }^{14}$ carried out a study in 92 children with reading disabilities, classified as scotopic or non-scotopic. The diagnosis was made using the Irlen Differential Perceptual
Schedule and participants were randomly assigned to one of six treatment groups using colored or clear overlays. The authors showed significant reading improvements among scotopic children with the preferred colored overlay filter in comparison with those not using filters, whereas non-scotopic children showed no change. The study had serious selection bias where children were pointed to the study by teachers who had identified reading difficulties. Although the authors claimed double-blind procedures, it is arguable whether they carried them out properly. Also, it is worth noting that the study lacked validated instruments for assessment.

Ritchie et al. ${ }^{43}$ examined 75 children with below-average reading ability measured by validated instruments and evaluated by an Irlen-certified professional. Fourteen children were excluded from the study because they could not participate in the screening test for the syndrome. Of the remaining 61 children, 47 were diagnosed with SI (77\%). Three of these 47 were removed from the main analysis because they knew their ideal lens color. All the children were tested using prescribed filters, placebo and a clear filter. In both the control and the experimental groups, the filters had no significant effect on reading. The three children who were not in the blinding showed a significant improvement in the reading test, indicating a significant placebo effect, even though it was considered biased and non-representative, as well as a possible bias of analysis once a positive result was removed from the main analysis. Of the children diagnosed with the syndrome, 44 participated in a parallel study, in which 22 received a colorless filter and 22 received the ideal filter. There was no significant difference between the two groups in any of the readings. The same group was followed for a year; 22 children (30\%) were still using the filter or the lens and, those who were still available for analysis showed evident reading deterioration. Ritchie et al. also used the same group of patients in a sequel study in order to follow up the group. Data showed no pattern to distinguish the IS children who continued treatment from those who did not. The authors also report that in their study, like others, about $50 \%$ of the colored lens users abandoned the device after one year.

Vidal-López ${ }^{44}$ tested the theories of two models of colored lens effects for reading speed: attribution bias theory and the visual stress theory associated with reading. The attribution bias consists of the placebo effect that the lenses may possess. A visual stress model (or cortical hyperexcitability) was proposed based on standard contrast tests. This test causes symptoms of visual stress in some individuals, which are mitigated by the use of specific lenses ${ }^{54}$. According to this theory, lenses can normalize electrical discharge patterns in hyperexcitable neurons. The experimental group consisted of individuals with high scores on tests and had a preferred color for reading. The control group consisted of individuals with low scores and who did not have a preferred reading lens. Only the reading speed from the control group with colored lenses showed a statistically significant improvement. The 
results did not corroborate the visual stress theory since the improvement in reading speed was not higher in the experimental group during the visual stress test. In addition, the data supported the idea that the use of colored lenses may have induced changes in the individual's reading pattern (even if statistically not significant), as proposed by the attribution bias theory. Alternatively, lenses may have changed the individual's motivation and expectation (placebo effect), leading to more engagement in the reading task, transferring his disability to an external cause (the lenses).

\section{DISCUSSION}

In Griffiths et al. ${ }^{12}$, the authors cite the book "The Irlen Revolution", in which the author argues that only the colored filters provided by the Irlen Institute are effective in treating the syndrome, but there is no scientific basis for such an assertion. In addition, in the studies found on the Irlen Institute, a consistent definition of the disease was applied, as well as a diagnostic procedure involving test materials provided by the professionals trained by the institute. The book by Helen Irlen could not be accessed by the authors of this study, nor is there any evidence on the efficacy of Irlen lenses alone.

\section{Sample size, group selection and study type}

The summaries presented herein show the enormous heterogeneity in group selection, sample size estimations and validity, as well as major flaws in study design. In this particular case, it is remarkable that the control group had the worst measured reading and visual parameters in comparison with all the experimental groups ${ }^{29}$. It was also related that studies had their groups selected from special schools or from teachers' criteria ${ }^{14}$. Another finding was that language proficiency testing was scarce, with a notable case where the control group, which had English as their first language, was more likely to be the participants who read significantly faster with their overlay ${ }^{33}$. The data showed the control group had only $39 \%$ of individuals with English as their first language and the experimental group with the overlay comprised 67\% English speakers. Also, a common feature was the fragility or even absence of tests for the control group and severe imbalance among the case and control groups. Self-reported reading discomfort or difficulties were widespread among the studies presented here.

The IS diagnosis was a major focus of criticism. More than the vagueness of IS symptoms ${ }^{55}$, some authors affirmed that when visual perceptual distortions were reported when reading, and such symptoms were alleviated by colored filters, then the individual was affected by the condition ${ }^{24}$.

The IS diagnosis is generally based on tests developed by Irlen and colleagues ${ }^{56}$, comprising three steps: (1) a questionnaire of 32 questions about ocular and reading symptoms;
(2) a series of visual tasks, such as responding to questions about visual distortions while observing images; (3) an assessment of the degree of improvement of the presented symptoms and improvement in the visual and reading tasks while using the colored lenses ${ }^{23}$. At the end of the reading task, all subjects were asked: How do your eyes feel? Did you have any difficulties with the print? Did you have any difficulties with the light? Is there anything you would like to add? The test remains unpublished.

Despite the claims of validity for IS diagnostic tools, the most cited validation studies raise several concerns. Only four studies performed validation tests, two of them are unpublished dissertations $\mathrm{s}^{57,58}$, and two $\mathrm{tw}^{59,60}$ do not include critical aspects of the validation processes. Data from these articles do not support proper validation by methodological limitations such as the construction of the tool and its premises, sample size estimation, validation of the construct, internal scores, accuracy and reliability, even when compared with other scales of perception ${ }^{8}$. It is recognized, even by supporters of the tests ${ }^{37}$, that the severe limitations to addressing estimates of prevalence provided by Irlen, due to her not providing any data or diagnostic criteria, result in the lack of an objective diagnostic test. Hence, it is not surprising that strong criticism relies specifically on IS detection.

The method has low sensitivity and low specificity ${ }^{9}$. Even readers without the syndrome, if they have poor reading, can be diagnosed with the syndrome. The opposite is also true: individuals who may have the syndrome to a lesser degree may not be diagnosed. Therefore, the method is criticized as hyper-inclusive ${ }^{5}$. Some of these tests were restricted to individuals who underwent the training program at the Irlen Institute and became certified Irlen screeners ${ }^{44}$. In this case, even if it was a validated test, many of the tests performed within these studies should be regarded as invalid or flawed by the lack of such certification.

Another point of criticism is the fact that a significant part of the test for IS is based upon the patients' preferences for a specific color. It was specified by Evans et al. ${ }^{28}$ that when the patient showed preference for a colored overlay, then this color should be adopted for reading if one found it helpful. In other words, the preference for a color might define the treatment. This has profound effects, especially on children.

Moreover, selecting individuals for study, with the objective of evaluating the effect of the lenses, induces a selection bias. Irlen Syndrome is diagnosed on the basis of either the sustained voluntary use of an overlay or an immediate improvement (of more than 5\%) on the Wilkins Rate of Reading Test ${ }^{37}$. Wilkins developed this test to isolate and measure the effect of visual factors on reading ${ }^{37}$. Most reading tests are designed to evaluate high-level reading skills, but not the contribution of visual factors to reading. However, the Wilkins Rate of Reading Test is criticized for being devised to be visually crowded and to maximize visual discomfort by simulating the striped effect, which is known to cause a pattern glare 
effect. Visual discomfort is maximized by reducing the spacing between words in order to achieve this effect ${ }^{35}$. This may affect reading performance in the presence of eye movement control difficulties. In this sense, when separating an experimental group with IS individuals and a control group without IS, the experimental group inherently respond to the lenses in the diagnostic method. This scenario occurred in many studies ${ }^{15-18}$. Nevertheless, even with this flagrant bias, most of the studies did not present statistically significant differences between the control and experiment groups, with adequate lenses or placebo ${ }^{15,16,20}$.

\section{Interventions}

Among the arsenal of possible lenses, there are 55 different colors that can be prescribed in combinations of pairs, trios or even quartets for the final prescription. That is, there are a total of 368,830 possible combinations. Thus, there is a considerable random effect present in this modality of treatment, which cannot be considered valid for clinical practice and, therefore, is seriously questioned ${ }^{4}$. The lenses are prescribed using the Intuitive Colorimeter ${ }^{\circledR}$, an instrument developed by Wilkins and patented by the Medical Research Council ${ }^{37}$.

Another point of concern is the fact that no wavelength measurement is performed in order to determine the actual color of the filter. Only in four studies was this procedure conducted. The tones of blue or pink or yellow are a continuum along the spectrum and very precise measurements are possible. Furthermore, the environmental luminance was barely considered in a few studies, which undoubtedly interfered in the final color received by the patients' retina. Under any psychophysical test, this omission is considered a fatal flaw for the experiment and is like saying that a certain drug dosage is not measured before administration. The feasibility of such experimental control and the possibility of variable control was not observed in the studies.

\section{Studies conclusion}

Many studies ${ }^{33-37}$ contradicted their own results, even claiming that, although not statistically significant, their study had shown improvements in reading speed in children with severe self-reported reading difficulties, when compared with other participants. There were also statements that, when no test detected significant differences in reading speed between the groups, the "obvious reason" was ascribed to the test ${ }^{48}$.

More than fallacies, many of them resort to highly-speculative mechanisms in order to find possible, but far from feasible, mechanisms. Regarding the most accepted underlying mechanisms for IS, two models are proposed as a possible role of the lenses when any improvement is detected. The most identified is the placebo effect. Individual characteristics about the perception of being involved in a study for their own reading deficiency possibly increases motivation to carry out the reading task presented. In addition, the participants transfer their disability to some external resolution (the lenses), easily applicable, and not internal resolution (more reading practice, slow reading etc. ${ }^{44}$.

Another possible mechanism is to alleviate cortical neuronal hyperexcitability present in individuals with the syndrome. Clinical studies have failed to identify such a mechanism and the effect of lenses on it. Neuroimaging studies ${ }^{47}$, however, show results that may support this theory. In one case report ${ }^{53}$, a cortical response was verified in the child identified with IS. However, the study showed a low level of scientific evidence, several experimental flaws and has not yet been reproduced. Finally, the anatomical and functional knowledge about parvocellular, magnocellular and koniocellular pathways, the mechanisms underlying visual information processing, is robust and well established. The magnocellular pathway is insensible to colors and to the visible spectrum, being responsible for stereopsis. These facts expose the unfounded use of colored filters and reinforce that the reduction of contrast could worsen the reading ability ${ }^{61}$.

\section{Overall features}

Concerns are expressed ${ }^{62}$ about the validity of IS and Irlen lenses due to the lack of evidence, and the fact that colored overlays achieve no significant results. Experiments on reading problems involving suppression of distractors, background pattern removal or foreground clutter have some evidence of function ${ }^{63}$. The IS advocates have been urged to publish their data in order to make them available to the scientific community, if this evidence, in fact, exists ${ }^{61}$.

It is worth noting that most of the IS and Irlen lenses advocates generally rely on potentially outdated research for their argument. Several improvements in the understanding of visual attention and its neural correlates have been attained. From the 122 articles retrieved in the present study, only 15 were published in the second decade of the 2000s. Even so, data from these previous studies ignored findings from their time ${ }^{64}$ and still claimed improvements from colored lenses for everyone.

Another point to consider is the fact that a large bulk of data has been produced about the influence of environmental colors on cognitive tasks, perceptual performance and the sleep cycle, to mention a few. It is remarkable that IS advocates changed their position slightly ${ }^{33}$, shifting from the controversial lacking evidence denomination of IS to MearesIrlen syndrome/visual stress and then to a vaguer term, visual stress, supposedly as the same condition. This suggests that academic discussions about IS maybe confined to a restricted community. Not surprisingly, the strongest data challenging the findings surrounding IS were presented outside this community. Even so, the heterogeneity emerges as a critical issue when analyzing these studies, as shown below.

Taking everything in account, the American Academy of Ophthalmology and the American Academy of Pediatrics published a guideline, in $2014^{65}$, for clinical decision making. After 34 years of research, since IS was described in 1980, 
scientific evidence on disease diagnosis and lens therapy still show invalidities to corroborate the applicability of such processes. In this way, both academies do not recommend the use of colored lenses for treating reading deficits, similar to data presented by Galuschka and Schulte-Körne ${ }^{5}$, and from another study by these authors, on reading disabilities ${ }^{66}$. Finally, the dilemma posed by Sagan ${ }^{67}$ on the persistence of selected conclusions is applicable to IS and its colored lenses advocates in a way that indicates that stronger evidence is still needed.

In conclusion, after more than three decades since the description of IS, despite the quality of the current evidence regarding the subject it does not allow us to completely refute the disease in terms of symptomatology. The present study found data arguing that the screening and diagnostic tests are at least questionable, if not valid. Despite the IS treatments and the claims of its harmlessness or, at least, innocuous effects, more evidence-based medicine is needed. The prescription of colored lenses specifically for this spectrum of symptoms should not be recommended. Adequate scientific evidence is the only way to dismiss the doubts about the real usefulness of such treatment. Also, IS supporters have not been successful in either the recognition and identification of IS per se, or with possible and effective treatments. In fact, the clinical descriptions do not seem definitive and, therefore, any proposal of a therapeutic approach will have methodological difficulties. Under the light of the scientific method, the rhetoric controversy only favors the colored arguments of IS advocates. To our knowledge, we have presented the most comprehensive review on IS to date. We conclude that the use of colored lenses or overlays to ameliorate reading difficulties cannot be endorsed, and that any benefits reported by individuals in clinical settings are likely to be the result of placebo, practice or the Hawthorne effect, consistent with previous reviews and advice from several associations. Therefore, it is still necessary to develop an accurate diagnosis of IS to develop further therapeutic approaches.

\section{References}

1. Meares $O$. Figure/ground, brightness contrast, and reading disabilities. Visible Language 1980; 14: 13-29.

2. Irlen HL. Scotopic sensitivity? Irlen syndrome: hypothesis and explanation of the syndrome. J Behav Optom 1994; 5(62): 65-6.

3. Pieh $\mathrm{CH}$, Lagrèze WA. A critical view of alternative methods for treating visual complaints. Ophthalmologe.2008;105(3):281-4. DOI: 10.1007/s00347-007-1647-1

4. Uccula A, Enna M, Mulatti C. Colors, colored overlays, and reading skills. Front Psychol. 2014; 29(5): 833. doi: 10.3389/ fpsyg.2014.00833

5. Galuschka K, Schulte-Körne G: Clinical practice guideline:The diagnosis and treatment of reading and/or spelling disorders in children and adolescents. Dtsch Arztebl Int. 2016;113:279-86. DOI: 10.3238/arztebl.2016.0279

6. Nandakumar K, Leat SJ. Dyslexia: a review of two theories. Clin Exp Optom 2008; 9(4):333-40. DOI: 10.1111/j.1444-0938.2008.00277.x.

7. Loew SJ, Watson K. A prospective genetic marker of the visualperception disorder Meares-Irlen syndrome. Percept Mot Skills 2012;114(3):870-82. DOI:10.2466/24.10.11.27.PMS.114.3.870-882

8. Sparkes DL, Robinson GL, Dunstan H, Roberts TK. Plasma cholesterol levels and Irlen syndrome: preliminary study of 10to 17-yr.- old students. Percept Mot Skills 2003; 97(3): 743-52. DOI:10.2466/pms.2003.97.3.743

9. Griffiths PG, Taylor RH, Henderson LM, Barrett BT. The effect of coloured overlays and lenses on reading: a systematic review of the literature. Ophthalmic Physiol Opt 2016: 36(5): 519-44. DOI:10.1111/opo.12316

10. Mitchell C, Mansfield D, Rautenbach S. Coloured filters and reading accuracy, comprehension and rate: A placebocontrolled study. Perceptual Motor Skills. 2008;106(2):517-532. DOI:10.2466/PMS.106.2.517-532

11. Moher D, Liberati A, Tetzlaff J, Altman DG, The PRISMA Group. Preferred Reporting Items for Systematic Reviews and MetaAnalyses:The PRISMA Statement. BMJ. 2009;338:b2535. DOI:10.1136/bmj.b2535
12. OCEBM Levels of Evidence Working Group. The Oxford 2011 Levels of Evidence. Oxford Centre for Evidence-Based Medicine. http://www. cebm.net/index.aspx?o=5653; accessed 2018, July.

13. General Guidelines for Methodologies on Research and Evaluation of Traditional Medicine. United States of American: Essential Medicines and Health Products Information Portal - A World Health Organization resource. http://apps.who.int/medicinedocs/en/d/ Jwhozip42e/13.1.html ; accessed 2018, July.

14. O'Connor PD, Sofo F, Kendall L, Olsen G. Reading disabilities and the effects of colored filters. J Learn Disabil. 1990;23(10):597-603. DOI:10.1177/002221949002301006

15. Scheiman M, Blaskey P, Ciner EB, Gallaway M, Parisi M, Pollack K, Selznick R. Vision characteristics of individuals identified as Irlen Filter candidates.J Am Optom Assoc. 1990;61(8): 600-5. PMID: 2394899

16. Blaskey P, Scheiman M, Parisi M, Ciner EB, Gallaway M, Selznick R. The effectiveness of Irlen filters for improving reading performance: a pilot study. J Learn Disabil.1990;23(10):604-12. DOI:10.1177/002221949002301007

17. Robinson GL, Conway RN. The effects of Irlen colored lenses on students' specific reading skills and their perception of ability: A 12-month validity study. J Learning Disabil. 1990;23(10):589-596. DOI:10.1177/002221949002301005

18. Martin F, Mackenzie B, Lovegrove W, McNicol D. Irlen lenses in the treatment of specific reading disability: An evaluation of outcomes and processes. Australian J Psychol 1993; 45(3): 141-150. DOI:10.1080/00049539308259131

19. Carroll TA, Mullaney P, Eustace P. Dark adaptation in disabled readers screened for Scotopic Sensitivity Syndrome. Percept Mot Skills. 1994; 78(1):131-41. DOI: 10.2466/pms.1994.78.1.131

20. Evans BJ, Cook A, Richards IL, Drasdo N. Effect of pattern glare and colored overlays on a stimulated-reading task in dyslexics and normal readers. Optom Vis Sci 1994; 71(10): 619-28. DOI: 10.1097/00006324-199410000-00004

21. Lopez R, Yolton RL, Kohl P, Smith DL, Saxerud MH. Comparison of Irlen scotopic sensitivity syndrome test results to academic and visual performance data. J Am Optom Assoc. 1994; 65(10): 705-14. PMID: 7995893 
22. Sawyer C, Taylor S, Willcocks S. Transparent coloured overlays and specific learning difficulties. AEP (Association of Educational Psychologists) Journal. 1994;(4), 217-220. DOI:10.1080/0266736940090404.

23. Wilkins AJ, Evans BJW, Brown JA, Busby AE, Wingfield AE, Jeanes RJ, Bald J. Double masked placebo controlled trial of precision spectral filters in children who use coloured overlays. Ophthal Physiol Opt 1994;14:365-370. DOI:10.1111/j.1475-1313.1994.tb00126.x

24. Evans BJW, Busby A, Jeanes R, Wilkins AJ. Optometric correlates of Meares-Irlen Syndrome: a Matched group study. Ophthal Physiol Opt 1995; 15(5): 481-7. DOI:10.1046/j.1475-1313.1995.9500063j.x

25. Spafford CS, Grosser GS, Donatelle JR, Squillace SR, Dana JP. Contrast sensitivity differences between proficient and disabled readers using colored lenses. J Learn Disabil. 1995;28(4):240-52. DOI:10.1177/002221949502800406

26. Evans BJW, Wilkins AJ, Brown J, Busby A, Wingfield A, Jeanes $\mathrm{R}$, Bald J. A preliminary investigation into the aetiology of Meares-Irlen syndrome. Ophthal Physiol Opt 1996; 16(4): 286-96. https://doi.org/10.1046/j.1475-1313.1996.95001190.x

27. Ciuffreda KJ, Scheiman M, Ong E, Rosenfield M, Solan HA. Irlen lenses do not improve accommodative accuracy at near. Optom Vis Sci. 1997;74(5):298-302. DOI: 10.1097/00006324-199705000-00026

28. Evans BJ, Patel R, Wilkins AJ, Lightstone A, Eperjesi F, Speedwell L, Duffy J. A review of the management of 323 consecutive patients seen in a specific learning difficulties clinic. Ophthalmic Physiol Opt. 1999;19(6):454-66. DOI:10.1111/j.1475-1313.1999.00465.x

29. Robinson GL, Foreman PJ. Scotopic sensitivity/Irlen syndrome and the use of coloured filters: a long-term placebo-controlled study of reading strategies using analysis of miscue. Percept Mot Skills 1999;88(1):35-52. DOI:10.2466/pms.1999.88.1.35

30. Robinson GL, Foreman PJ. Scotopic sensitivity/Irlen syndrome and the use of coloured filters: a long-term placebo controlled and masked study of reading achievement and perception of ability. Percept Mot Skills.1999;89(1): 83-113. DOI:10.2466/pms.1999.89.1.83

31. Robinson GL, Foreman PJ, Dear KB. The familial incidence of symptoms of scotopic sensitivity//rlen syndrome: comparison of referred and mass-screened groups. Percept Mot Skills. 2000;91(3):707-24. DOI:10.2466/pms.2000.91.3.707

32. Bouldoukian J, Wilkins AJ, Evans BJW. Randomised controlled trial of the effect of coloured overlays on the rate of reading of people with specific learning difficulties. Ophthalmic Physiol Optics. 2002;22(1):55-60. DOI:10.1046/j.1475-1313.2002.00002.x

33. Evans BJ, Joseph F. The effect of coloured filters on the rate of reading in an adult student population. Ophthalmic Physiol Opt. 2002;22(6):535-45. DOI:10.1046/j.1475-1313.2002.00071.x

34. Scott L, McWhinnie H, Taylor L, Stevenson N, Irons P, Lewis E, Evans M, Evans B, Wilkins A. Coloured overlays in schools: Orthoptic and optometric findings. Ophthalmic Physiol Opt. 2002;22(2):156-165. DOI: 10.1046/j.1475-1313.2002.00009.x

35. Northway N. Predicting the continued use of overlays in school children - A comparison of the Developmental Eye Movement test and the Rate of Reading test. Ophthalmic Physiol Opt. 2003;23(5):457-464. https://doi.org/10.1046/j.1475-1313.2003.00144.x

36. Waldie M, Wilkins A. How big does a coloured overlay have to be? Ophthalmic Physiol Opt. 2004;24(1):57-60. DOI:10.1046/j.1475-1313.2003.00169.x

37. Kriss I, Evans BJW. The Relationship between Dyslexia and Meares-Irlen Syndrome.J Res Reading. 2005;28(3):350-364. DOI:10.1111/j.1467-9817.2005.00274.x

38. Hollis J, Allen PM. Screening for Meares-Irlen sensitivity in adults: can assessment methods predict changes in reading speed? Ophthalmic Physiol Opt. 2006;26(6):566-71. DOI:10.1111/j.1475-1313.2006.00401.x

39. Riddell PM, Wilkins A, Hainline L. The effect of coloured lenses on the visual evoked response in children with visual stress. Optometry Vision Sci. 2006;83(5):299-305. DOI:10.1097/01.opx.0000216125.83236.af

40. Kruk R, Sumbler K, Willows D. Visual processing characteristics of children with Meares-Irlen syndrome. Ophthalmic Physiol Opt 2008; 28(1): 35-46. DOI:10.1111/j.1475-1313.2007.00532.x

41. Nichols SA, McLeod JS, Holder RL, McLeod HS. Screening for dyslexia, dyspraxia and Meares-Irlen syndrome in higher education. Dyslexia 2009;15(1): 42-60. DOI:10.1002/dys.382

42. Taub MB, Shallo-Hoffmann J, Steinman S, Steinman B. The effect of colored overlays on reading eye movements in adults. J Behav Optometry. 2009;20(6), 143-149.

43. Ritchie SJ, Della Sala S, Mclntosh RD. Irlen colored overlays do not alleviate reading difficulties. Pediatrics 2011;128(4):932-8. DOI:10.1542/peds.2011-0314

44. Vidal-López J. The role of attributional bias and visual stress on the improvement of reading speed using colored filters. Percept Mot Skills. 2011;112(3):770-82. DOI: 10.2466/15.19.24.PMS.112.3.770-782

45. Ritchie SJ, Della Sala S, Mclntosh RD. Irlen colored filters in the classroom: A 1-year follow-up. Mind Brain Educ. 2012;6(2):74-80. DOI:10.1111/j.1751-228X.2012.01139.x

46. Chang M, Kim SH, Kim JY, Cho YA. Specific visual symptoms and signs of Meares-Irlen syndrome in Korean. Korean J Ophthalmol. 2014; 28(2):159-63. DOI:10.3341/kjo.2014.28.2.159

47. Kim JH, Seo HJ, Ha SG, Kim SH. Functional magnetic resonance imaging findings in Meares-Irlen syndrome: a pilot sudy. Korean J Ophthalmol. 2015;29(2):121-5. DOI:10.3341/kjo.2015.29.2.121

48. Loew SJ, Rodríguez C, Marsh NV, Jones GL, Núñez JC, Watson K. Levels of Visual Stress in Proficient Readers: Effects of Spectral Filtering of Fluorescent Lighting on Reading Discomfort. Span J Psychol. 2015;10(18):E58. DOI:10.1017/sjp.2015.59

49. Alanazi MA, Alanazi SA, Osuagwu UL. Evaluation of visual stress symptoms in age-matched dyslexic, Meares-Irlen Syndrome and normal adults. Int J Ophthalmol 2016; 9(4): 617-24. DOI: 10.18240/ijo.2016.04.24

50. Garcia ACO, Momensohn-Santos TM, Vilhena DA. Effects of Spectral Overlays on Reading Performance of Brazilian Elementary School Children. Folia Phoniatr Logop. 2017;69(5-6):219-225. DOI: 10.1159/000484139.

51. Robinson GL, Foreman PJ, Dear KB. The familial incidence of symptoms of Scotopic Sensitivity/Irlen syndrome. Percept Mot Skills 1996; 83(3): 1043-55. DOI:10.2466/pms.1996.83.3.1043

52. Scrase R. An evaluation of a multi-sensory speaking-computer based system (Starcross-IDL) designed to teach the literacy skills of reading and spelling. Br J Educational Technol. 1998; 29 (3): 211-24. DOI:10.1111/1467-8535.00065

53. Wilkins A, Neary C. Some visual, optometric and perceptual effects of coloured glasses. Ophthalmic Physiol Opt. 1991;11(2):163-71. DOI:10.1111/j.1475-1313.1991.tb00216.x

54. Chouinard BD, Zhou Cl, Hrybouski S, Kim ES, Cummine J. A functional neuroimaging case study of Meares-Irlen syndrome/ visual stress (MISViS). Brain Topogr. 2012; 25(3): 293-307. DOI:10.1007/s10548-011-0212-z

55. Robinson GL, McGregor NR, Roberts TK, Dunstan RH, Butt $H$. A biochemical analysis of people with chronic fatigue who have Irlen Syndrome: speculation concerning immune system dysfunction. Percept Mot Skills. 2001;93(2): 486-504. DOI:10.2466/pms.2001.93.2.486

56. Irlen H: Irlen Reading Perceptual Scale (IRPS). Perceptual Development Corporation, 2003. 
57. Haag SR. The IDPS Children's Form: a validity study. Unpublished Master of Science thesis, California State Univer., Los Angeles, 1984.

58. Miller LS. Scotopic sensitivity and reading disability. Unpublished Master of Education thesis, California State Univer, Los Angeles, 1984.

59. Robinson GL, Hopkins BR, Davies T. The incidence of symptoms of Scotopic Sensitivity Syndrome in secondary school populations: A preliminary study. Bull Learn Disabil. 1995;5;36-56.

60. Tyrrell R, Holland K, Dennis D, Wilkins A. Coloured overlays, visual discomfort, visual search and classroom reading. J Res Reading. 1995;18(1):10-23. DOI:10.1111/j.1467-9817.1995.tb00064.x

61. BMJ. 2014;349:g4872.

62. Williams GS. Irlen syndrome: expensive lenses for this ill defined syndrome exploit patients. BMJ 2014 (29):349

63. Das M, Bennett DM, Dutton GN. Visual attention as an important visual function: an outline of manifestations, diagnosis and management of impaired visual attention. Br J Ophthalmol. 2007;91:1556-1560. DOI:10.1136/bjo.2006.104844

64. Menacker SJ, Breton ME, Breton JR, Gole GA. Do tinted lenses improve the reading performance of dyslexic children? A Cohort Study. Arch Ophthalmol 1993;111:213-87. PMID: 8431158.

65. AAO-AAP Joint Statement: Learning Disabilities, Dyslexia, and Vision - Reaffirmed 2014 Available at https://www.aao.org/clinicalstatement/joint-statement-learning-disabilities-dyslexia-vis : accessed 2018/07.

66. Galuschka K, Ise E, Krick K, Schulte-Körne G.

Effectiveness of Treatment Approaches for Children and Adolescents with Reading Disabilities: A Meta-Analysis of Randomized Controlled Trials. Plos One. 2014;9(2):e89900. DOI:10.1371/journal.pone.0089900

67. Sagan C.A demon haunted world. London: Headline Book; 1997 Chapter 10; p. 160 